\title{
Familial clustering and presence of maternal influence on the transmission of type 2 diabetes in South Indians
}

\author{
Lalitha R. ${ }^{1}$, Anil Kumar R. ${ }^{2}$, Shetty S.B. ${ }^{3}$ \\ ${ }^{1}$ Dr. Lalitha R, Assistant Professor, ${ }^{2}$ Dr. Anil Kumar R, Assistant Professor, ${ }^{3}$ Dr. Surekha B Shetty, Assistant Professor, \\ all authors are affiliated with Karnataka Institute of Endocrinology and Research, Bengaluru, Karnataka, India.
}

Corresponding Author: Dr. Lalitha R, Assistant Professor, Karnataka Institute of Endocrinology and Research, Bengaluru, Karnataka, India. Email: drlalithashivaprakash@gmail.com

\begin{abstract}
Type 2 diabetes mellitus (T2D) is a chronic metabolic disorder, characterized by hyper glycaemia caused by impaired glucose homeostasis and represents a serious public health problem. T2D is a multi-factorial disorder depending on complex interactions between environmental factors and genetic variants. Objective: To evaluate the degree of familial aggregation and maternal influence on the transmission of type 2 diabetes in the South Indian population. Methodology: A total of 1063 subjects with type 2 diabetes with knowledge of history of presence or absence of diabetes in relatives were randomly recruited. 652 were male and 411 were female. Results: This study showed familial clustering and maternal transmission in our study population. $78.3 \%$ of the subjects had at least one relative with diabetes. Familial aggregation was significant with presence of diabetes in $1^{\text {st }}$ degree relative like parents and in siblings. $2^{\text {nd }}$ degree relatives too had significantly associated with diabetes to a similar extent like $1^{\text {st }}$ degree relatives.Patient's age range between 50-59 showed highest incidence of diabetes at 44\% followed by $37 \%$ in age group $40-49$. Our study showed an advancement of incidence of diabetes by one decade compared to similar studies in different regions. Conclusion: Maternal factors do play an important role in the incidence of diabetes, prevalence of diabetes. Several factors may be involved in this in terms of polycystic ovaries, gestational diabetes, malnourishment during pregnancy, and other socioeconomic factors. We need studies and further research in ascertaining the exact mechanisms. Familial aggregation is common and may help us to screen for diabetes in high risk populations. Preventive strategies for type 2 diabetes should be directed at these high risk groups.
\end{abstract}

Key words: Familial clustering, maternal, Type 2 diabetes mellitus, South Indians

\section{Introduction}

Type 2 diabetes mellitus (T2D) is a chronic metabolic disorder, characterized by hyperglycemia caused by impaired glucose homeostasis, and represents a serious public health problem. Prevalence of diabetes is increasing at the global level with large variation from one population to another depending on the ethnic origin. [1,2]. In India, similar to in other developing countries, there is a growing alarm for the important socioeconomic impact of the disease-high medical costs and disturbed quality of life [3,4].

T2D is a multifactorial disorder depending on complex interactions between environmental factors and genetic variants. Incidence of T2D is triggered by a genetic susceptibility, as reported by monozygous twin studies

Manuscript received: $24^{\text {th }}$ July 2018

Reviewed: $2^{\text {nd }}$ August 2018

Author Corrected: $9^{\text {th }}$ August 2018

Accepted for Publication: $13^{\text {th }}$ August 2018 and familial aggregation in several populations [5-8]. Although, with recent advances in defining the molecular basis of T2D, the mode of inheritance of this disease is still debated. Several studies reported that the risk of diagnosed T2DM increases when one or both parents are affected and some studies suggest that persons whose mothers had diabetes are more likely to develop diabetes themselves, compared with persons whose fathers had diabetes [9-12]. Numerous studies have concluded that individuals with maternal history of diabetes are at a higher risk of developing the disease than individuals with a paternal diabetes history. To evaluate the degree of familial aggregation and maternal influence on the transmission of type 2 diabetes in the South Indian population. To ascertain the peak onset of diabetes in the studied population.To assess if maternal factors have a major influence on the development of diabetes in the progeny. 


\section{Materials and Methods}

Subjects with type $2 \mathrm{DM}$ attending the outpatient department at Karnataka Institute of Endocrinology and research, Bengaluru were recruited for the study. Detailed family history of the subjects recruited were elicited and recorded. Those who were doubtful of the family history were excluded. A total of 1063 subjects with type 2 diabetes were randomly recruited. The study recorded confirmed diabetes in relatives as mentioned below

- $1^{\text {st }}$ degree relative included parents, brothers and sisters.

- $2^{\text {nd }}$ degree relative included maternal and paternal uncles, aunts, and cousins.

- $3^{\text {rd }}$ degree relatives included grandparents and second cousins.

\section{Inclusion criteria}

1. Adult subjects above the age of 18 years are included.

2. Subjects with a diagnosis of type 2 diabetes in the above age criteria.

3. Subjects with available information on status of diabetes in close relatives are recruited.

\section{Exclusion criteria}

1. Subjects below the age of 18 years.

2. Pregnant women with diabetes.

3. Type 1 adult diabetic subjects.

4. Other types of diabetes other than type 2 diabetes are excluded on basis of clinical history.

5. Subjects belonging to other than South Indian states of Karnataka, Andhra Pradesh, Telangana, Kerala and Tamil Nadu.

Statistical Analysis: SPSS Software was used to analyze the results and derive at the risk ratios and relations.

Pearson correlation was used for assessing the significance and power of risk association with the $p$ values of $<0.05$ being significant positive association.

\section{Results}

Study subjects with presence of family history: Among the study subjects, 652 were male and 411 were female. (table1). It was observed that the first-degree relatives had a strong correlation $1^{\text {st }}$ Degree relative with diabetes were seen in $64.25 \%$ of individuals with either a mother, father or a sibling as diabetic. $2^{\text {nd }}$ degree relatives being diabetic were seen in $38.1 \%$ and $3^{\text {rd }}$ degree relatives being diabetic were seen in $22.4 \%$. (Fig 1 )

Subject's father with diabetes were seen in $28.9 \%(\mathrm{n}=307)$ and without diabetes in $71.1 \%(\mathrm{n}=756)$. (Table 2)

Subject's mother with diabetes were seen in $35.3 \%(n=375)$ and no-diabetes in $64.7 \%(n=688)$. (Table-3)

Subject's sisters being diabetic seen in $32.2 \%$ and brothers being diabetic in $35.7 \%$.

Both parents with diabetes was seen in $23.7 \%$ of male subjects compared to $13.1 \%$ in female subjects.

Presence of diabetes in siblings is significant and has a comparable risk to that of diabetes in parents.

There is no significant difference between the presence of diabetes in brothers or sisters.

Patients aged with 50-59 were 44\% followed by 37\% aged 40-49. Our study showed anearlier shift by 1 decade peaking between 50-59, this trend may continue in future with a shift of prevalence in younger age groups leading to higher economic burden on the health.

$78.3 \%$ of the subjects had at least one relative with diabetes. Familial aggregation is significant with presence of diabetes in $1^{\text {st }}$ and $2^{\text {nd }}$ degree relative. Diabetes in siblings is significant with risk comparable to diabetes in parents. The age of onset in age group 40-49 is comparable to 50-59 years which signifies earlier onset and has implications on the prevalence of diabetes with its burden on the healthcare system. Excess maternal transmission is significant with frequency in mother being high at $63.2 \%$ compared to $24.6 \%$ in fathers. The calculated $p$ value 0.001 is significant.

Table-1: Frequency Table Indicating Subject's Gender Data.

\begin{tabular}{|c|c|c|c|c|c|}
\hline \multicolumn{2}{|c|}{} & Frequency & Percent & Valid Percent & Cumulative Percent \\
\hline \multirow{3}{*}{ Valid } & Male & 652 & $\mathbf{6 1 . 3}$ & 61.3 & 61.3 \\
\cline { 2 - 6 } & Female & 411 & $\mathbf{3 8 . 7}$ & 38.7 & 100.0 \\
\cline { 2 - 6 } & Total & $\mathbf{1 0 6 3}$ & $\mathbf{1 0 0 . 0}$ & $\mathbf{1 0 0 . 0}$ & \\
\hline
\end{tabular}




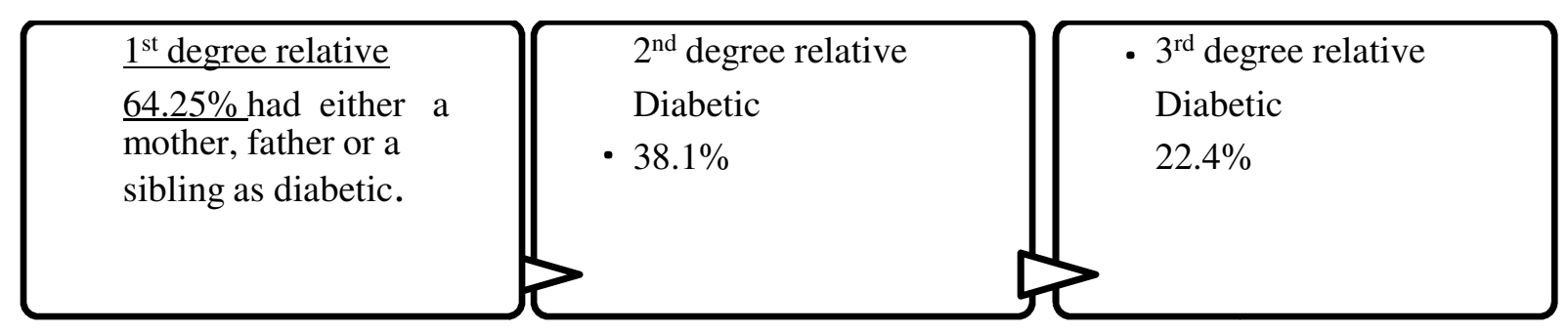

Figure 1

Table-2: Frequency Table indicating Subject's Father's Diabetic History Data.

\begin{tabular}{|c|c|c|c|c|c|}
\hline \multicolumn{2}{|c|}{} & Frequency & Percent & Valid Percent & Cumulative Percent \\
\hline \multirow{3}{*}{ Valid } & Diabetic & 307 & 28.9 & 28.9 & 28.9 \\
\cline { 2 - 6 } & Non Diabetic & 756 & $\mathbf{7 1 . 1}$ & 71.1 & 100.0 \\
\cline { 2 - 6 } & Total & $\mathbf{1 0 6 3}$ & $\mathbf{1 0 0 . 0}$ & $\mathbf{1 0 0 . 0}$ & \\
\hline
\end{tabular}

Table-3: Frequency Table indicating Patient's Mother's Diabetic History Data.

\begin{tabular}{|c|c|c|c|c|c|}
\hline \multicolumn{2}{|c|}{} & Frequency & Percent & Valid Percent & Cumulative Percent \\
\hline \multirow{2}{*}{ Valid } & Diabetic & 375 & 35.3 & 35.3 & 35.3 \\
\cline { 2 - 6 } & Non Diabetic & 688 & $\mathbf{6 4 . 7}$ & 64.7 & 100.0 \\
\hline
\end{tabular}

Table-4: Either parent with diabetes

\begin{tabular}{|c|c|c|c|c|}
\hline & Father & \% & Mother & \% \\
\hline Male subject & 97 & $22.2 \%$ & 126 & $58.6 \%$ \\
\hline Female subject & 72 & $28.7 \%$ & 111 & $69.4 \%$ \\
\hline Total & $\mathbf{1 6 9}$ & $\mathbf{2 4 . 6 \%}$ & $\mathbf{2 3 7}$ & $\mathbf{6 3 . 2 \%}$ \\
\hline
\end{tabular}

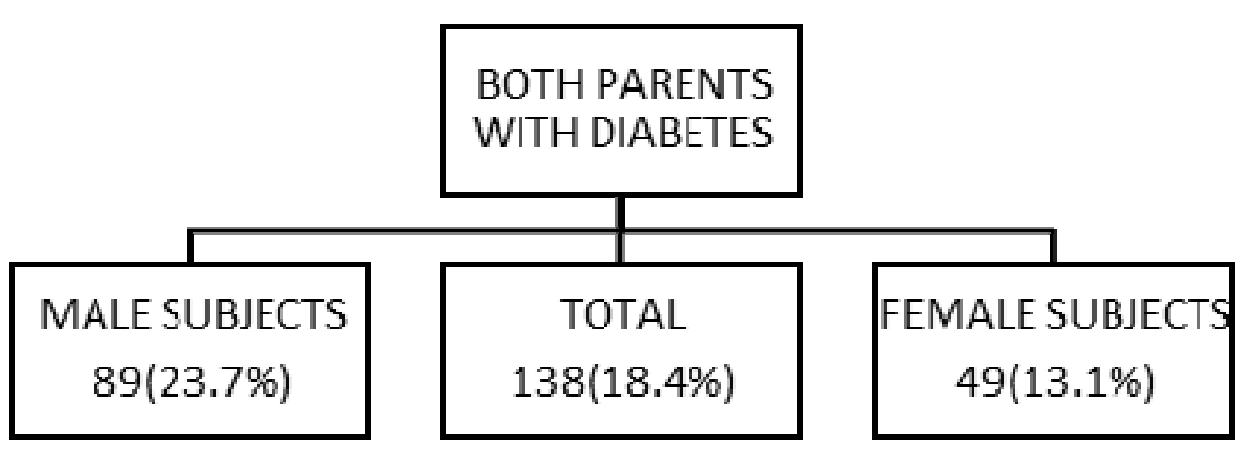

Figure 2 
Original Research Article

Table-5: Correlations between various variables under consideration.

\begin{tabular}{|c|c|c|c|c|c|c|c|c|c|}
\hline & & 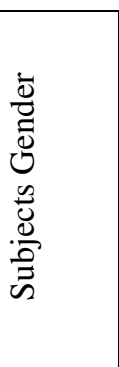 & 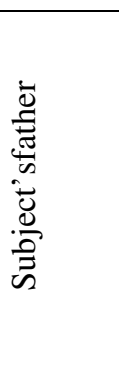 & 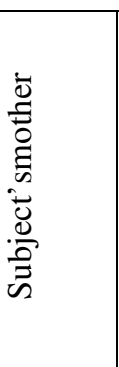 & 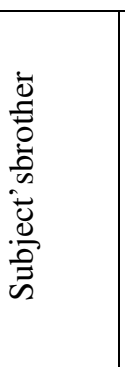 & 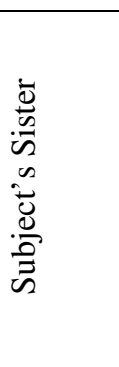 & 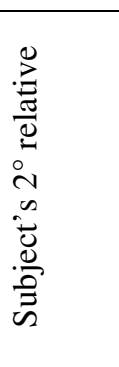 & 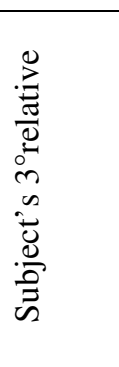 & 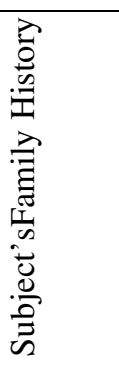 \\
\hline \multirow[t]{3}{*}{ Subject'sGender } & $\begin{array}{c}\text { Pearson } \\
\text { Correlation }\end{array}$ & 1 & -.010 & $-.061^{*}$ & $-.114^{* *}$ & $-.139^{* *}$ & -.014 & $-.069^{*}$ & $-.105^{* *}$ \\
\hline & Sig. (2-tailed) & & .749 & .048 & .000 & .000 & .659 & .024 & .001 \\
\hline & $\mathrm{N}$ & 1063 & 1063 & 1063 & 1062 & 1062 & 1063 & 1063 & 1063 \\
\hline \multirow[t]{3}{*}{ Subject'sfather } & $\begin{array}{c}\text { Pearson } \\
\text { Correlation }\end{array}$ & -.010 & 1 & $.129^{* *}$ & $.177^{* *}$ & $.112^{* *}$ & $.201^{* *}$ & $.096^{* *}$ & $.306^{* *}$ \\
\hline & Sig. (2-tailed) & .749 & & .000 & .000 & .000 & .000 & .002 & .000 \\
\hline & $\mathrm{N}$ & 1063 & 1063 & 1063 & 1062 & 1062 & 1063 & 1063 & 1063 \\
\hline \multirow[t]{3}{*}{ Subject'smother } & $\begin{array}{c}\text { Pearson } \\
\text { Correlation }\end{array}$ & $-.061^{*}$ & $.129^{* *}$ & 1 & $.182^{* *}$ & $.161^{* *}$ & $.207^{* *}$ & $.114^{* *}$ & $.370^{* *}$ \\
\hline & Sig. (2-tailed) & .048 & .000 & & .000 & .000 & .000 & .000 & .000 \\
\hline & $\mathrm{N}$ & 1063 & 1063 & 1063 & 1062 & 1062 & 1063 & 1063 & 1063 \\
\hline \multirow[t]{3}{*}{ Subject'sbrother } & $\begin{array}{c}\text { Pearson } \\
\text { Correlation }\end{array}$ & $-.114^{* *}$ & $.177^{* *}$ & $.182^{* *}$ & 1 & $.380^{* *}$ & $.132^{* *}$ & $.105^{* *}$ & $.389^{* *}$ \\
\hline & Sig. (2-tailed) & .000 & .000 & .000 & & .000 & .000 & .001 & .000 \\
\hline & $\mathrm{N}$ & 1062 & 1062 & 1062 & 1062 & 1061 & 1062 & 1062 & 1062 \\
\hline \multirow[t]{3}{*}{ Subject'ssister } & $\begin{array}{c}\text { Pearson } \\
\text { Correlation }\end{array}$ & $-.139^{* *}$ & $.112^{* *}$ & $.161^{* *}$ & $.380^{* *}$ & 1 & .054 & $.094^{* *}$ & $.349^{* * *}$ \\
\hline & Sig. (2-tailed) & .000 & .000 & .000 & .000 & & .081 & .002 & .000 \\
\hline & $\mathrm{N}$ & 1062 & 1062 & 1062 & 1061 & 1062 & 1062 & 1062 & 1062 \\
\hline \multirow[t]{3}{*}{$\begin{array}{l}\text { Subject's } 2^{\circ} \\
\text { relative }\end{array}$} & $\begin{array}{c}\text { Pearson } \\
\text { Correlation }\end{array}$ & -.014 & $.201^{* *}$ & $.207^{* *}$ & $.132^{* *}$ & .054 & 1 & $.355^{* *}$ & $.399^{* *}$ \\
\hline & Sig. (2-tailed) & .659 & .000 & .000 & .000 & .081 & & .000 & .000 \\
\hline & $\mathrm{N}$ & 1063 & 1063 & 1063 & 1062 & 1062 & 1063 & 1063 & 1063 \\
\hline \multirow[t]{3}{*}{ Subject's $3^{\circ}$ relative } & $\begin{array}{c}\text { Pearson } \\
\text { Correlation }\end{array}$ & $-.069^{*}$ & $.096^{* *}$ & $.114^{* *}$ & $.105^{* *}$ & $.094^{* *}$ & $.355^{\text {** }}$ & 1 & $.278^{* *}$ \\
\hline & Sig. (2-tailed) & .024 & .002 & .000 & .001 & .002 & .000 & & .000 \\
\hline & $\mathrm{N}$ & 1063 & 1063 & 1063 & 1062 & 1062 & 1063 & 1063 & 1063 \\
\hline \multirow[t]{3}{*}{ Subject's F/H } & $\begin{array}{c}\text { Pearson } \\
\text { Correlation }\end{array}$ & $-.105^{* *}$ & $.306^{* *}$ & $.370^{* *}$ & $.389^{* *}$ & $.349^{* *}$ & $.399^{* *}$ & $.278^{* *}$ & 1 \\
\hline & Sig. (2-tailed) & .001 & .000 & .000 & .000 & .000 & .000 & .000 & \\
\hline & $\mathrm{N}$ & 1063 & 1063 & 1063 & 1062 & 1062 & 1063 & 1063 & 1063 \\
\hline \multicolumn{10}{|c|}{ *. Correlation is significant at the 0.05 level (2-tailed). } \\
\hline & & & & & & & & & \\
\hline
\end{tabular}




\section{Discussion}

Type 2 diabetes is a chronic metabolic disorders with multiple aetiopathological factors including genetic inheritance. The existence of excess maternal transmission of type 2 diabetes iscurrently debated (17-19). Both environmental and genetic hypotheses have been proposedas mechanisms for maternaltransmission (17, 19-22). Proposed environmental mechanisms include maternal effects onintrauterine environment. Behavioural risk factors preferentially passed on bymothers like dietary or physical activitybehaviours that increase the risk of obesityand diabetes.

Transmission of mitochondrialgenes (passed only from mother to children) is the most common genetic hypothesis. Excess maternal transmission of type 2 diabetes has not been consistently observed across races. Although this inheritance pattern has been observed inpopulations with lower prevalence of disease, North American, English, French, and Chinese populations, negative findings have been reported in atleast two ethnic groups with high prevalenceof diabetes (i.e., Hispanics and South Asian Indians, South Indians and Koreans) [15,22].

However, excessmaternal transmission has also been observed in Pima Indians. Different methods of quantifying excess maternal transmission make studies from different populations difficult to compare. Potential bias in the reporting of family history data and equivocal findings, especially between the various racial groups, have contributed to the controversy overthe existence of excess maternal transmission of diabetes $[17,18]$.

Although understanding the completenessand accuracy of diabetes family history data would seem to be necessary tothe study of patterns of inheritance, therehave been very few evaluations ofits quality and associated biases [17]. Studiesof excess maternal transmission wouldbe particularly sensitive to bias if thesubject's ability to provide complete andaccurate histories differed for the maternalversus paternal arms of the pedigree [18].

Preventive strategies for type 2 diabetes should be directed at these high risk groups. Factors that may be causing a shift towards an earlier age group need to be addressed and studied. Excess maternal transmission is significant with frequency in mother being high, $63.2 \%$ in mothers compared to $24.6 \%$ in fathers. A number of studies have shown an excess maternal transmission in different populations. Our study results showed similar results to De Silva et al in Srilankan population that an excess maternal transmission with familial aggregation [13]. This study group showed $78.3 \%$ of the subjects had at least one relative with diabetes. Investigation in previous study showed the parental transmission patterns of T2DM showing an excess of maternal transmission of T2D as mothers were implicated two times more frequently than fathers. This inheritance pattern has been reported for severalpopulations includingEnglish, French, South African, Chinese, North American, Caucasians and West Indian patients have shown similar results [23].

Viswanathan $M$ et al in a South Indian population showed that there is no maternal influence on the transmission of type 2 DM. Kim J et al also showed a lack of excess maternal transmission in Korean population [15].

In the CURES study the peak prevalence of diabetes was in 60-69 age group with $33 \%$ but in this study we have seen an advance of one 1 decade peaking between 50-59.16 Thistrend may continue in future with a shift of prevalence in younger age groups leading to higher economic burden on the health. Peak age of onset of diabetes in the study population is in between 50-59. The age group between 40-49 is comparable to that of 50-59 suggesting an earlier onset of diabetes. Mohan et al have shown in the CURES study a similar phenomenon of shift in onset of diabetes to earlier age group [16].

\section{Conclusion}

Maternal factors play an important role in the increasing prevalence of diabetes. The reasons for this need to be evaluated. Maternal nutrition during pregnancy, presence of GDM, diabetes during pregnancy, genetic and maternal side consanguity and other factors may play a role. Familial aggregation is common and may help us to screen for diabetes in high risk populations. Preventive strategies for type 2 diabetes should be directed at these high risk groups. Factors that may be causing a shift towards an earlier age group need to be addressed and studied. In our study we found an excess of maternal transmission and familial aggregationas against to a similar study in South Indian population. This may need further evaluation as to whether consanguineous marriages, maternal nutrition, intrauterine foetal growth, gestational diabetes, polycystic ovarian disease or other factors influence this 


\section{Original Research Article}

trend. Our study also addresses the need to educate and counsel these set of population to apply preferential screening and preventive strategies. In this study we have overcome the study bias by excluding subjects without a proper and confirmed knowledge of diabetes status in the first degree relatives.

Hence we can now address and look into factors that may contribute to this phenomenon in our population in future studies. IRB approval obtained and KIER ethics committee approval obtained.

\section{Contribution by authors}

Authors Dr Anil Kumar R and Dr Surekha Shetty have helped in study design and in the analysis of data. They have contributed to the discussion and preparation of manuscript.

Acknowledgement- The author would like to thank all the subjects and $\mathrm{Mr}$ Pradeep $\mathrm{BK}$ (Biocon) for assistance.

\section{Funding: Nil, Conflict of interest: None Permission of IRB: Yes}

\section{References}

1. Zimmet P, Alberti KG, Shaw J. Global and societal implications of the diabetes epidemic. DOI:10. 1038/ $414782 \mathrm{a}$

2. Zimmet PZKelly West Lecture 1991. Challenges in diabetes epidemiology--from West to the rest. Diabetes Care. 1992 Feb;15(2):232-52.

3. Lin T, Chou P, Lai MS et al. Direct costs-of-illness of patients with diabetes mellitus in Taiwan. Diabetes Res Clin Pract. 2001 Nov;54 Suppl1:S43-6.

4. Abid A, Amrouch C, Ben Hassine A, Jamoussi H, Bousetta A, Blouza S, Nagati K. Indirect cost of diabetes in Tunisian diabetic population. InDiabetologia 2003 Aug 1 (Vol. 46, pp. A434-A434). 175 FIFTH AVE, NEW YORK, NY 10010 USA: SPRINGERVERLAG.

5. Medici F, Hawa M, Ianari A, et al. Concordance rate for type II diabetes mellitus in monozygotic twins: actuarial analysis. DOI:10.1007/s001250051132

6. Zimmet P, Dowse G, Finch C, et al. The epidemiology and natural history of NIDDM--lessons from the South Pacific. Diabetes Metab Rev. 1990 Mar; 6 (2):91-124.
7. Erasmus RT, Blanco EB, Okesina AB, Arana JM, Gqweta Z, Matsha T. Importance of family history in type 2 black South African diabetic patients. Postgraduate medical journal. 2001 May 1;77(907):323-5.

8. Lee SC, Pu YB, Chow CC, et al. Diabetes in Hong Kong Chinese: evidence for familial clustering and parental effects. Diabetes Care. 2000 Sep;23(9):1365-8.

9. Knowler WC, Pettitt DJ, Savage PJ, Bennett PH. Diabetes incidence in Pima indians: contributions of obesity and parental diabetes. Am J Epidemiol. 1981 Feb;113(2):144-56.

10. Klein BE, Klein R, Moss SE, Cruickshanks KJ. Parental history of diabetes in a population-based study. Diabetes Care. 1996 Aug;19(8):827-30.

11. Karter AJ, Rowell SE, Ackerson LM, et al. Excess maternal transmission of type 2 diabetes. The Northern California Kaiser Permanente Diabetes Registry. Diabetes Care. 1999 Jun;22(6):938-43.

12. Young, C. A., Kumar, S., Young, M. J., \& Boulton, A. J. (1995). Excess maternal history of diabetes in Caucasian and Afro-originon-insulin-dependent diabetic patients suggests dominant maternal factors in disease transmission. Diabetes Research and Clinical Practice, 28 (1), 47-49.

13. De Silva SN, Weerasuriya N, De Alwis NM, De Silva MW, Fernando DJ. Excess maternal transmission and familial aggregation of Type 2 diabetes in Sri Lanka. Diabetes research and clinical practice. 2002 Dec 1; 58(3):173-7.

14. Arfa I, Abid A, Malouche D, Alaya NB, Azegue TR, Mannai I, Zorgati MM, Rayana MC, Ammar SB, Blousa- Chabchoub S, Romdhane HB. Familial aggregation and excess maternal transmission of type 2 diabetes in Tunisia. Postgraduate medical journal. 2007 May 1;83(979):348-51.

15. Viswanathan M, McCarthy MI, Snehalatha C, et al. Familial aggregation of type 2 (non-insulin- dependent diabetes mellitus in south India; absence of excess maternal transmission. DOI: 10.1002/ (SICI) 1096-9136 (199603) 13: 3<232::AID-DIA27>3.0.CO;2-7

16. Poongothai S, Anjana RM, Pradeepa R, et al. Prevalence of depression in relation to glucose intolerance in urban south Indians--the Chennai Urban Rural Epidemiology Study (CURES-76). doi: 10.1089/ dia. 2010.0081. 


\section{Original Research Article}

17. Cox NJ. Maternal component in NIDDM transmission. How large an effect? Diabetes. 1994 Jan; 43 (1):166-8.

18. Mitchell BD, Kammerer CM, Reinhart LJ, et al. Is there an excess in maternal transmission of NIDDM? Diabetologia. 1995 Mar;38(3):314-7.

19. Groop LC, Tuomi T. Non-insulin-dependent diabetes mellitus-- a collision between thrifty genes and an affluent society. Ann Med. 1997 Feb;29(1):37-53.

20. King MC, Lee GM, Spinner NB, et al. Genetic epidemiology. Annu Rev Public Health. 1984;5:1-52.
21. Freinkel N.Banting Lecture 1980. Of pregnancy and progeny. Diabetes. 1980 Dec;29(12):1023-35.

22. McCarthy M, Cassell P, Tran T, et al. Evaluation of the importance of maternal history of diabetes and of mitochondrial variation in the development of NIDDM. DOI:10.1002/(SICI)1096-9136(199605)13:5<420:: AID-DIA97 >3.0.CO;2-W

23. Knowler WC, McCance DR, Nagi DK, Pettitt DJ. Epidemiological studies of the causes of non-insulindependent diabetes mellitus.Causes of diabetes: Genetic and environmental factors.1993 Nov2:187-218.

\section{How to cite this article?}

Lalitha R, Anil Kumar R, Shetty S.B. Familial clustering and presence of maternal influence on the transmission of type 2 diabetes in South Indians. Int J Med Res Rev 2018;6(06):301-307.doi:10.17511/ijmrr. 2018.i06.02. 